\title{
2329. Dynamic response of bridge abutment to sand-rubber mixtures backfill under seismic loading conditions
}

\author{
Zhaoyu Wang ${ }^{1}$, Nan Zhang ${ }^{2}$, Qi Li ${ }^{3}$, Xiaohui Chen ${ }^{4}$ \\ $1,3,{ }^{4}$ College of Civil Engineering, Yancheng Institute of Technology, Yancheng, Jiangsu 224051, China \\ ${ }^{2}$ Department of Civil Engineering, University of Texas at Arlington, Arlington, Texas 76019, USA \\ ${ }^{2}$ Corresponding author \\ E-mail: 17ywang518@yahoo.com, ${ }^{2}$ zhangnanvictor47@hotmail.com, ${ }^{3} 1161959889 @ q q . c o m$, \\ 41260530098@qq.com
}

Received 30 August 2016; received in revised form 31 December 2016; accepted 2 January 2017

DOI https://doi.org/10.21595/jve.2017.17628

Abstract. China is located between the Pacific Ocean seismic belt and the Eurasian seismic belt where the seismic activity is frequent. Bridge plays a key role in transportation lifeline, but its construction and maintenance face potential seismic hazard in China, which may lead to a huge economic loss. This study investigates the dynamic response of bridge abutment to sand-rubber mixtures backfill under seismic loading conditions by finite element method. Sand-rubber mixtures is composed of waste fibers, rubber particles, sand and water with a certain mixing ratio and dry density It has been used as an anti-seismic backfill material for slopes, retaining walls, bridge structures and other geo-structures. A series of numerical simulations was carried out to evaluate the effectiveness of this new material as backfill material for bridge abutment. The seismic performance of bridge abutment with different backfill materials was analyzed with respect to settlements and accelerations of ground, foundation pile and bridge abutment. The results show that the sand-rubber mixture can be used as backfill material, and has a great potential in reducing the settlements and accelerations of ground and foundation pile.

Keywords: sand-rubber mixture, dynamic response, bridge abutment.

\section{Introduction}

With the rapid economic development, the number of road and bridge construction is increasing recently in China. However, in the meantime, some natural hazards such as landslide, earthquake occurs frequently, which causes failure or collapse of civil infrastructures. Hence, studying the soil-structure interaction under seismic loading conditions has important implications to the development of civil and geotechnical engineering. Many work has been reported in literature. For example, Ahmadi and Eskandari studied the vibration analysis of a rigid circular disk embedded in a transversely isotropic solid [1]. Pak investigated the seismic soil-structure interaction using boundary element methods [2], and elastodynamic response of pile under transverse excitations [3]. Other related work can be also found in literature [4-8].

As reported, bridge abutment is suffered from a severe damage after earthquake takes place particularly in Southeastern coastal area in China. As reported, backfill materials plays an important role to the bridge abutment regarding its static and dynamic response and performance. Apostoloum et al. studied the lift off effect of the rigid body into the field of earthquake engineering [9]. Housner found that the separation of the bridge foundation and foundation soils will be beneficial to the increase of earthquake resistance of the bridge under the action of strong earthquake [10]. Ciampoli and Pinto simulated the phenomenon of the pier in earthquake, and demonstrated the importance of interaction between the foundation soils and the bridge structure [11]. Priestley stated that the separation of bridge pier and foundation soils had a great influence on the total displacement of upper structure in earthquake [12]. In addition, Makris and Roussos found that dumping did not occur on a very slim rigid foundation [13]. Cremer et al. conducted numerical study to investigate the nonlinear dynamic characteristics of strip foundation by using the macro element [14]. Gazetas and Apostolou indicated that the failure of the bearing capacity 
under certain conditions were related to the characteristics of the structure foundation and the ground motion [15]. Kawashima proposed an effective method to reduce the isolation of bridge foundation, and the relevant theory was then applied to the design of bridge structure [16-18].

The use of tyres scrap, i.e. rubber material, can provide an alternative way to consume the huge stockpile of tyres scrap all over the world $[19,20]$. In recent years, various studies have been also conducted concerning the wide applications of sand-rubber mixtures in geotechnical engineering and construction of civil infrastructures [21-28]. In this study, the waste rubber and sand mixture (hereinafter referred to as sand-rubber mixture) was utilized as a backfill material for bridge abutment. The mixture is considered as a kind of lightweight material, which is made of waste fiber, rubber particles, sand and water in a certain mixing proportion. It has the advantages of light weight, high strength, and good independence. Construction technology is simple and convenient, the strength and density can be adjusted, and the price is low. Due to the existence of fibers, the reinforcing effect of the fibers can increase the tensile strength of sand-rubber mixture. In addition, the waste fiber and the waste rubber can be reused to solve the problem of waste material recycling, and potential environmental pollution. The sand-rubber mixture can be also used to replace soft soil layer or as a backfill material. It leads to the reduction of the upper load for foundation soils, improvement of stability of the foundation, static and seismic performance, and the settlement and displacement of foundation soils. The use of sand-rubber mixture also has a huge economic and social benefits and can meet the increasing demand of road building materials for the rapid development of highway construction and other civil infrastructures. Therefore, the sand-rubber mixture has a great potential in a wide range of engineering applications.

This paper presents a numerical simulation of dynamic response of bridge abutment to sand-rubber mixture backfill under seismic loading conditions. Four different backfill materials including backfill soil, $10 \% \mathrm{RS}, 20 \% \mathrm{RS}$ and $30 \% \mathrm{RS}$ (Note: percentage refers to the mixing ratio of rubber by dry weight) were selected in the modeling to compare the dynamic response of bridge abutment under different rubber contents. Simulation results were analyzed and discussed with respect to ground settlement, ground acceleration, displacement and acceleration of foundation pile, and settlement and acceleration of bridge abutment. Through the comparison among the four backfill materials, the seismic performance of bridge abutment with sand-rubber mixture backfill was investigated.

\section{Finite element modeling}

A three-dimensional model was developed in Midas to study the dynamic response of bridge abutment to sand-rubber mixture backfill. Midas GTS is a geotechnical and tunnel finite element analysis software for analyzing static and dynamic response of structures. In addition, three different sand-rubber mixtures and one common backfill soil were selected in the simulation for the comparison. The dynamic performance of bridge abutment and foundation pile to the four different backfill materials was systematically analyzed based on the simulation results.

\subsection{Model development}

A three-dimensional model was developed in this study which consists of five parts: backfill material, clay layer, sand layer, soft rock layer, bridge abutment and foundation piles as shown in Fig. 1. It is noted that the foundation piles have the same length of $12 \mathrm{~m}$ underneath the bridge abutment ending at the top of the soft rock layer. The 3D model of bridge abutment with backfill material, foundation soils and foundation piles is shown in Fig. 2.

\subsection{Material properties}

Summary of material properties is presented in Table 1. Four different backfill materials were selected in the model, which are backfill soil, $10 \% \mathrm{RS}, 20 \% \mathrm{RS}$ and $30 \% \mathrm{RS}$. According to Yuan 
[28], the properties of the four backfill materials are presented in Table 2. It is noted the fiber used in the sand-rubber mixture is the waste polypropylene fiber which has an extremely high elastic modulus of greater than $3500 \mathrm{MPa}$ and tensile strength of greater than $400 \mathrm{MPa}$ to improve the bearing capacity and reduce the settlement of foundation soils. The mixing ratio of the fiber in the four-different sand-rubber mixtures was the same which was $0.8 \%$ by weight. Moreover, due to the high elastic modulus of the fiber, the elastic modulus of the mixtures is supposed to be increased accordingly. Based on the Choi [29] study, the elastic modulus of the mixtures was determined as shown in Table 2. Additionally, the engineering design parameters of foundation piles are presented in Table 3. Twenty steel pipe piles with the same diameter of $0.6 \mathrm{~m}$ and wall thickness of $0.012 \mathrm{~m}$ were used in the model.
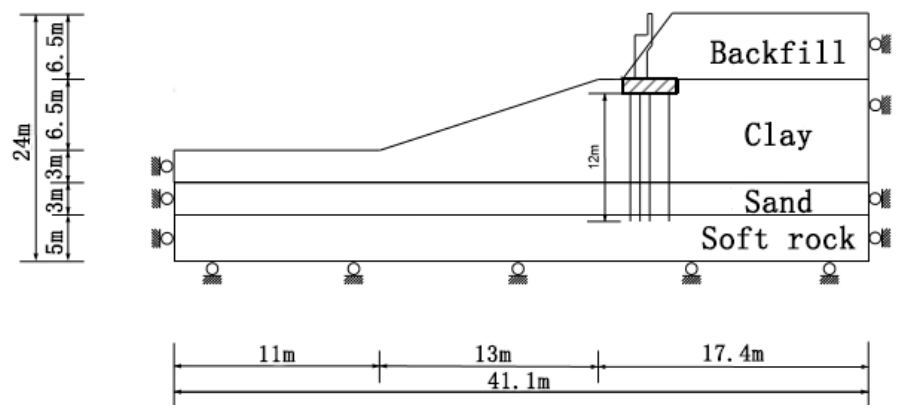

Fig. 1. Schematic of cross section of model

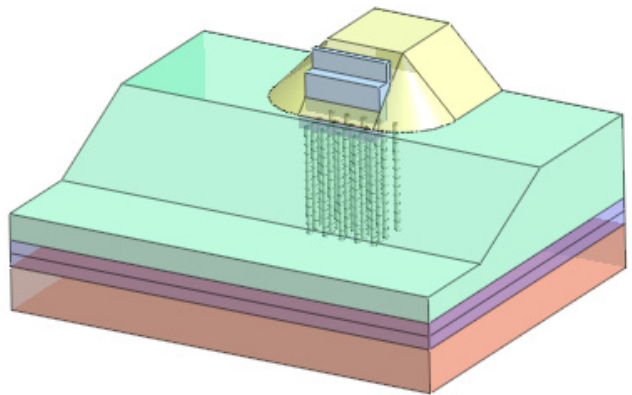

Fig. 2. 3D model of bridge abutment with backfill material, foundation soils and foundation piles

Table 1. Summary of material properties

\begin{tabular}{|l|c|c|c|c|c|}
\hline \multicolumn{1}{|c|}{ Name } & Soft rock & Sand & Clay & Backfill soil & Concrete abutment \\
\hline Elastic modulus $E\left(\mathrm{kN} / \mathrm{m}^{2}\right)$ & $2,000,000$ & 35,000 & 10,000 & 50,000 & $23,000,000$ \\
\hline Poisson ratio $u$ & 0.25 & 0.3 & 0.35 & 0.3 & 0.18 \\
\hline Bulk unit weight $\gamma\left(\mathrm{kN} / \mathrm{m}^{3}\right)$ & 23 & 18 & 16 & 16.5 & 25 \\
\hline Saturated unit weight $\gamma_{\text {sat }}\left(\mathrm{kN} / \mathrm{m}^{3}\right)$ & 23 & 19 & 17 & 17.5 & 25 \\
\hline Cohesion $c\left(\mathrm{kN} / \mathrm{m}^{2}\right)$ & 200 & 10 & 100 & 20 & 0 \\
\hline Friction angle $\varphi$ & 35 & 34 & 12 & 30 & 0 \\
\hline Tensile strength $\left(\mathrm{kN} / \mathrm{m}^{2}\right)$ & 20 & 1 & 10 & 2 & - \\
\hline
\end{tabular}

Table 2. Properties of backfill materials

\begin{tabular}{|l|c|c|c|c|}
\hline \multicolumn{1}{|c|}{ Name } & Backfill soil & $10 \%$ RS & $20 \%$ RS & $30 \%$ RS \\
\hline Cohesion $c\left(\mathrm{kN} / \mathrm{m}^{2}\right)$ & 20 & 20 & 20 & 20 \\
\hline Bulk unit weight $\gamma\left(\mathrm{kN} / \mathrm{m}^{3}\right)$ & 16.5 & 15.6 & 14.5 & 13.3 \\
\hline Saturated unit weight $\gamma_{\text {sat }}\left(\mathrm{kN} / \mathrm{m}^{3}\right)$ & 17.5 & 16.6 & 15.5 & 14.3 \\
\hline Friction angle $\varphi$ & 30 & 46 & 50 & 52 \\
\hline Elastic modulus $E\left(\mathrm{kN} / \mathrm{m}^{2}\right)$ & 50,000 & 110,000 & 100,000 & 90,000 \\
\hline
\end{tabular}


Table 3. Material properties of foundation piles

\begin{tabular}{|l|c|}
\hline \multicolumn{1}{|c|}{ Name } & Foundation pile \\
\hline Elastic modulus $E\left(\mathrm{kN} / \mathrm{m}^{2}\right)$ & $2.10 \mathrm{E}+08$ \\
\hline Poisson ratio $u$ & 0.3 \\
\hline Bulk unit weight $\gamma\left(\mathrm{kN} / \mathrm{m}^{3}\right)$ & 78 \\
\hline
\end{tabular}

\subsection{Meshing}

In order to ensure the coupling between the generated meshes, the 3D model was "printed and engraved" in front of the grid (the specified curve or vertex was projected onto the specified surface, based on the shape of the projection in the face to generate a line or point). When the mesh was divided on the surface, these lines and points were reflected. And then the hybrid mesh generator was used to generate the grid. In the static analyses, the bottom of the model was fixed, the front and rear boundaries were constrained along $X$ axis to the displacement, the left and the right boundary were constrained along $Y$ axis to the displacement, and the pile was constrained by the rotation with respect to $Z$ axis. In the dynamic analyses, the ground surface spring was used to define the boundary conditions, and the bottom of the model was fixed, and the pile was constrained by the rotation with respect to $Z$ axis. In the finite element model analyses, each layer of foundation soils was described by the three-dimensional solid element, and connected in the form of a common node. In addition, three-dimensional entity structure unit was defined by 8 nodes, each node had 3 degrees of freedom along the $X, Y, Z$ axes. Considering the nonlinearity of material in the model, Mohr Coulomb elastic plasticity model was used for backfill material and sub-grade soils, concrete elastic model was used for bridge abutment and foundation piles. The total number of element was 6135, and the number of nodes was 2098.

The dynamic analyses were carried out on the ground $X$ direction of 1940, Centro Site El, and vertical seismic wave was shown in Fig. 3. On the moment of settlement, abutment displacement, pile top displacement and pile were analyzed. In this paper, the use of seismic waves is commonly used in the seismic analyses of the classic Centro El seismic waves with duration of $37.68 \mathrm{~s}$, and the peak of $0.7777 \mathrm{~g}$ at $6.78 \mathrm{~s}$.

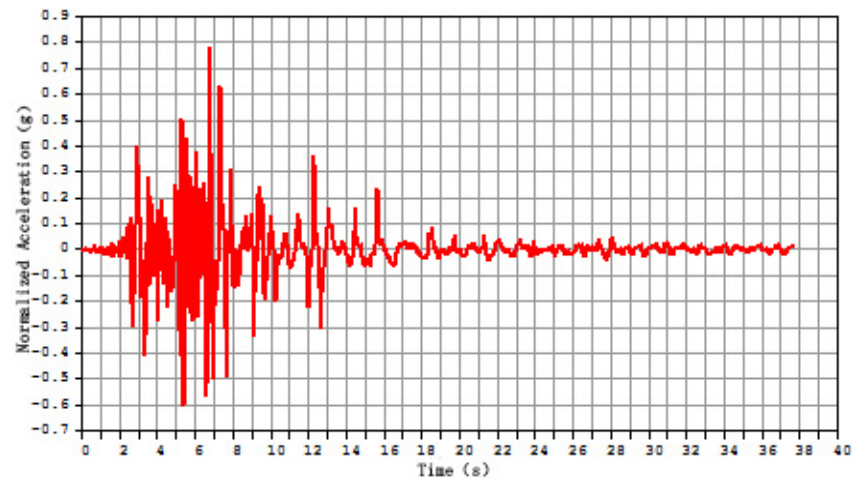

Fig. 3. Acceleration-time diagram earthquake (El Centro, 1940)

\section{Results and discussion}

\subsection{Analyses of ground settlement}

Ground settlement analyses has important implications in comparing the seismic performance of different backfill materials. Layout of survey point for ground settlement and acceleration analyses is shown in Fig. 4.

Time history curve of ground settlement for different backfill materials is shown in Fig. 5. Under seismic loads, fluctuations of ground settlement for backfill soil was much greater than that 
for the sand-rubber mixtures backfill. However, it is indicated that there was no too much difference in ground settlement among three different sand-rubber mixtures. Since the mixtures have characteristics of lightweight, high strength, and it contains fibers, leading to a relatively high tensile strength. Hence, the overall bearing capacity of ground is increased due to the positive effect on the resistance to subsidence, which protects the foundation and extends its service life. The comparison of ground settlement among three mixtures at the seismic peak value (i.e. $6.8 \mathrm{~s}$ ) shows that the settlement with $20 \%$ RS was decreased by $9.3 \%$ compared to $10 \%$ RS, and the settlement with $30 \%$ RS was decreased by $9.3 \%$ compared to $20 \%$ RS. For foundation with sand--rubber mixtures, the settlement of $10 \%$ RS was larger than $20 \%$ RS, the settlement of $30 \%$ RS was the smallest. Thus, the larger the rubber content the foundation soils has, the stronger the ability to reduce foundation settlement is.

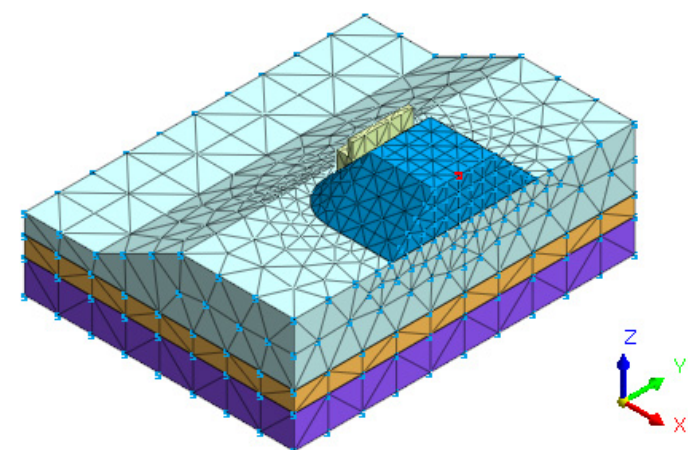

Fig. 4. Layout of survey point for ground settlement and acceleration analyses

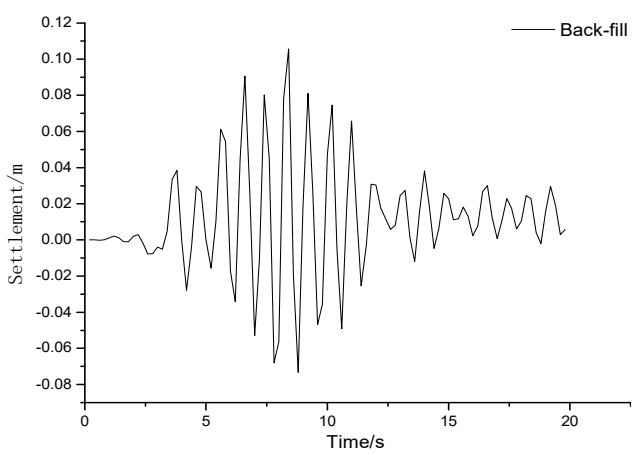

a) Backfill

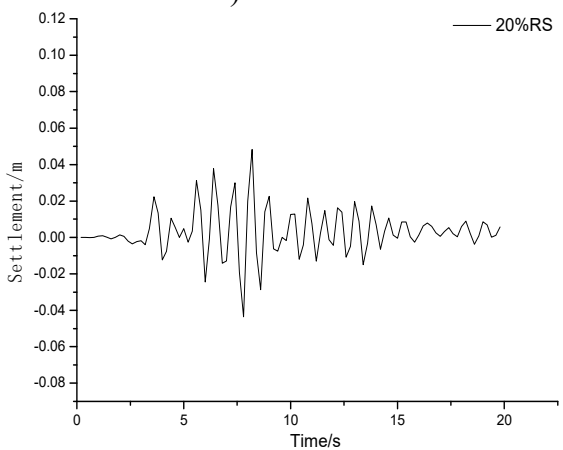

c) $20 \% \mathrm{RS}$

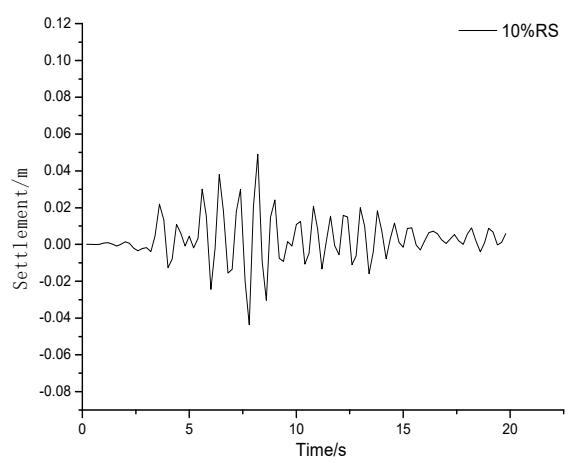

b) $10 \% \mathrm{RS}$

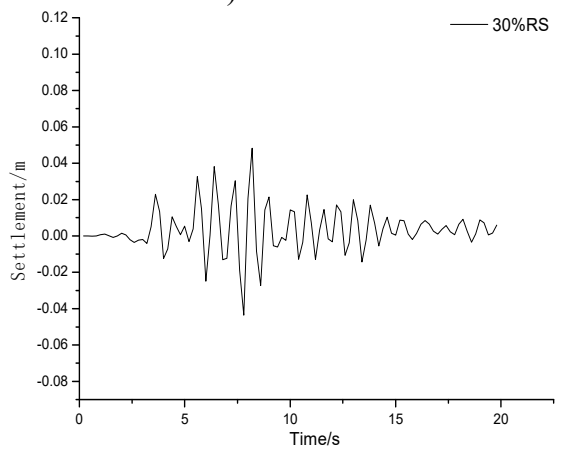

d) $30 \% \mathrm{RS}$

Fig. 5. Time history curve of ground settlement for different backfill materials 


\subsection{Analyses of ground acceleration}

Fig. 6 present the time history curve of ground acceleration for different backfill materials. It is indicated that the fluctuation of acceleration was relatively stable during 0-3 s, while it was increased considerably during 3-8 s, but became gradually after $8 \mathrm{~s}$. The characteristics of volatility of four different backfill materials were quite similar to the that of seismic wave propagation. It is also found that the difference of ground acceleration between the backfill soil and the sand-rubber mixtures backfill was very small. Compared to the backfill soil, the maximum ground acceleration for $10 \%$ RS was reduced by $35 \%$. Moreover, it decreased as the rubber content increased as shown in Fig. 7. From the calculation, the decrease in the maximum ground acceleration is $3.92 \%$ for $20 \% \mathrm{RS}$ as compared to $10 \% \mathrm{RS}$, and $5.48 \%$ for $30 \% \mathrm{RS}$ as compared to $20 \%$ RS. Hence, the sand-rubber mixture backfill can greatly reduce the ground acceleration, thereby this kind of lightweight material plays a key role in protecting the foundation.

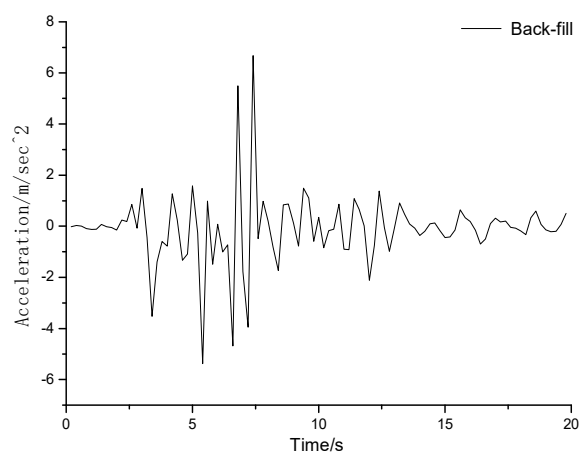

a) Backfill

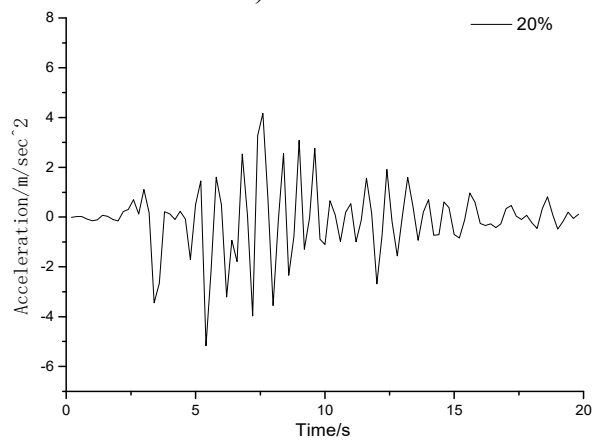

c) $20 \% \mathrm{RS}$

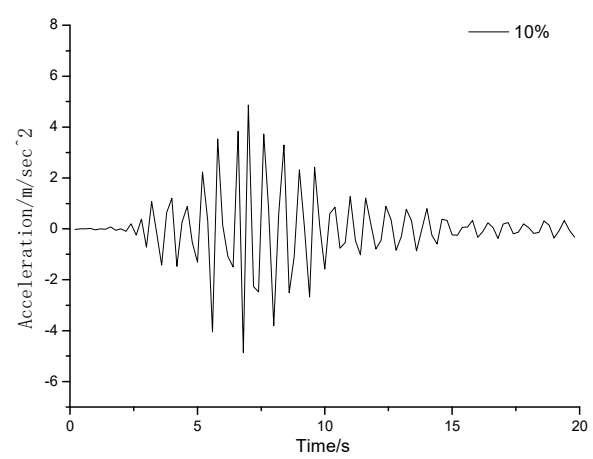

b) $10 \% \mathrm{RS}$

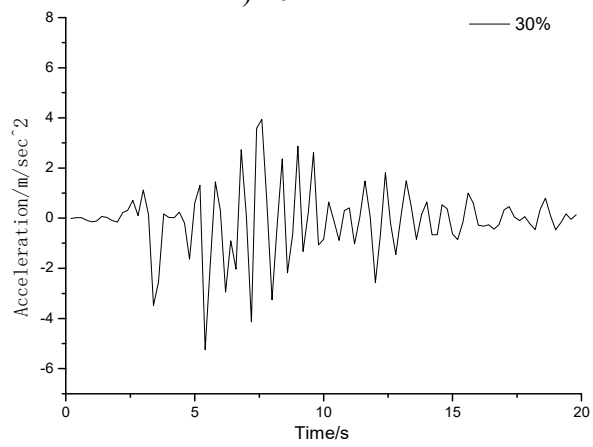

d) $30 \% \mathrm{RS}$

Fig. 6. Time history curve of ground acceleration for different backfill materials

\subsection{Analyses of pile top settlement}

The analyses of pile top settlement are important in the analyses of dynamic response of bridge abutment and foundation soils. The analyses of pile top settlement were performed through the three-dimensional model simulation in this study. Selected foundation pile for settlement analyses is shown in Fig. 7. Static and dynamic analyses of pile including pile vertical displacement, pile top acceleration and pile top bending moment were investigated. When the foundation is subjected to seismic load, the settlement of pile top can be obtained from the top of the pile.

Fig. 8 indicate the time history curves of settlement at top of foundation pile for different backfill materials. By comparing the static analyses results, it is found that the pile top vertical settlement of foundation backfill soil was greater than the pile top vertical settlement of the sand-rubber mixtures backfill. As the rubber content increased, the vertical settlement of pile top 
was decreased. The smaller the vertical settlement of the pile is, the better the stability of the foundation is. Thus, foundation with sand-rubber mixtures backfill is better than that with backfill soil. Comparison of pile top settlement among three mixtures at the peak value of seismic wave crest (i.e. $6.8 \mathrm{~s}$ ), it is found that the settlement of pile topfor $20 \% \mathrm{RS}$ was decreased by $12.3 \%$ compared to $10 \% \mathrm{RS}$, and the settlement of pile top for $30 \% \mathrm{RS}$ was decreased by $7 \%$ compared to $20 \%$ RS. It can be concluded that the sand-rubber backfill with higher rubber content can reduce pile top settlement more than that with lower rubber content.

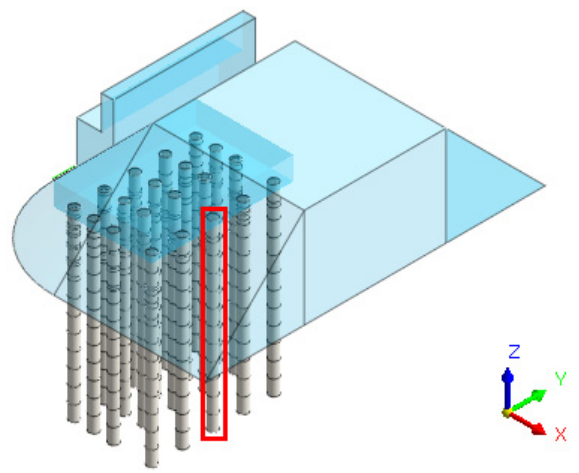

Fig. 7. Selected foundation pile for settlement analyses

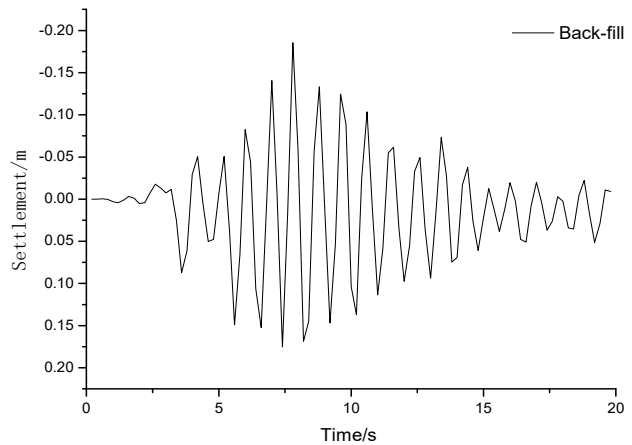

a) Backfill

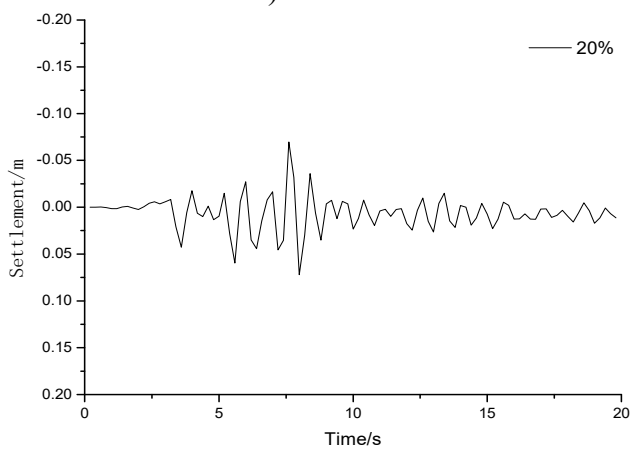

c) $20 \% \mathrm{RS}$

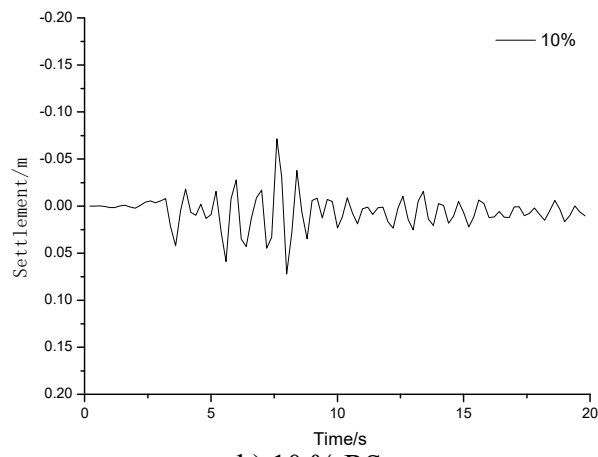

b) $10 \% \mathrm{RS}$

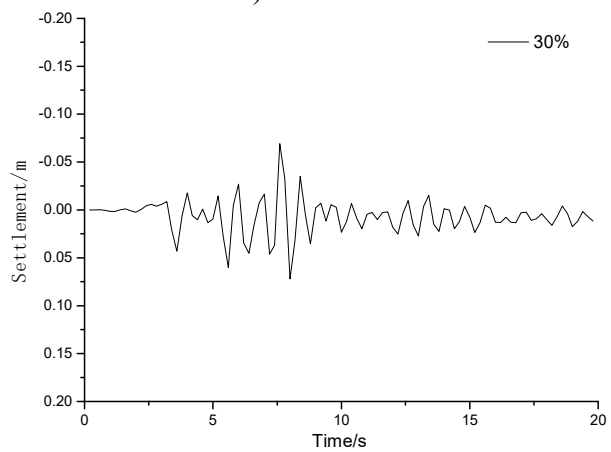

d) $30 \% \mathrm{RS}$

Fig. 8. Time history curves of displacement at top of foundation pile for different backfill materials

In Fig. 8, under the same seismic wave action, the four kinds of pile top $x$ to the settlement of different. It can be clearly seen that the settlement for the backfill soil was obviously larger than that for the sand-rubber mixtures backfill. The maximum settlement of the $10 \% \mathrm{RS}$ backfill was reduced by $61.10 \%$ compared to that of the backfill soil. There was little difference among the three sand-rubber mixtures backfill, which is due to the low shear modulus and high damping ratio 
of mixtures. The maximum extent of seismic energy dissipation, and the deformation of the foundation is related to the mechanical properties and the content of rubber used in the mixtures, which plays a significant role in the absorption of shock wave energy. It is seen that the settlement of the pile head can be greatly reduced when using the sand-rubber mixture backfill. But with the increase of rubber content in mixtures, the settlement at top of foundation pile is decreased slightly.

\subsection{Analyses of pile top acceleration}

Fig. 9 indicate the time history curves of acceleration at top of foundation pile for different backfill materials. According to the input data, the acceleration time history curve of pile top can be sorted out. It is found that foundation pile acceleration for backfill soil was greater than $10 \%$ $\mathrm{RS}$, and the fluctuations was also greater than $10 \% \mathrm{RS}$. Comparison of pile top acceleration among three mixtures at seismic wave peak (i.e. $6.8 \mathrm{~s}$ ), the pile top acceleration for $20 \%$ RS was decreased by $2.1 \%$ compared to $10 \%$ RS, and the pile top acceleration for $30 \%$ RS was decreased by $1.1 \%$ compared to $20 \% \mathrm{RS}$. It is indicated that the larger rubber content the sand-rubber mixtures has, the stronger the ability to reduce pile top acceleration is.

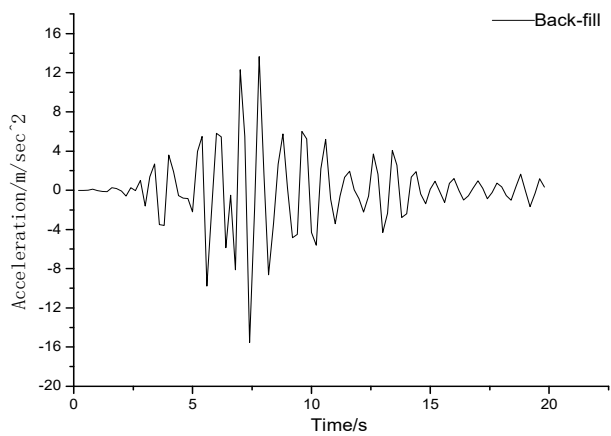

a) Backfill

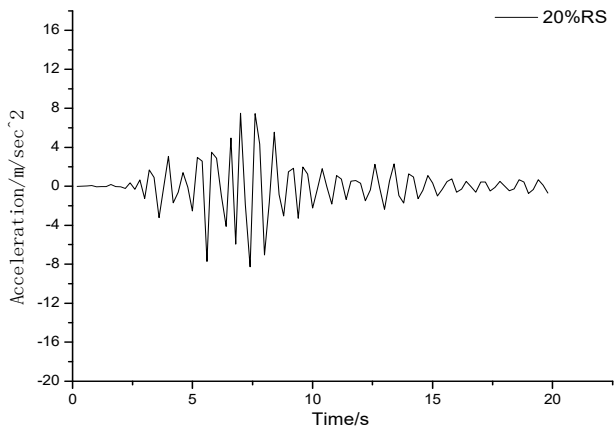

c) $20 \% \mathrm{RS}$

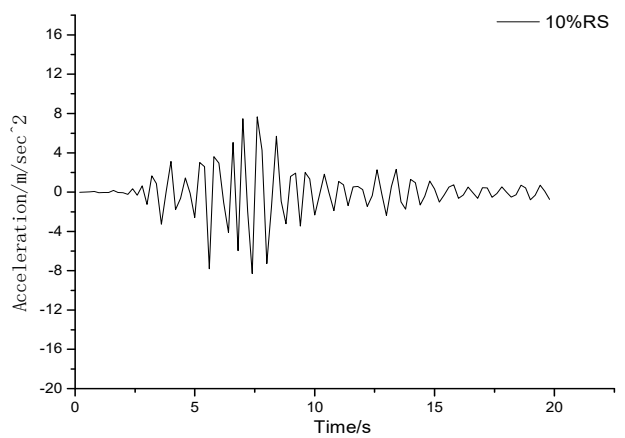

b) $10 \% \mathrm{RS}$

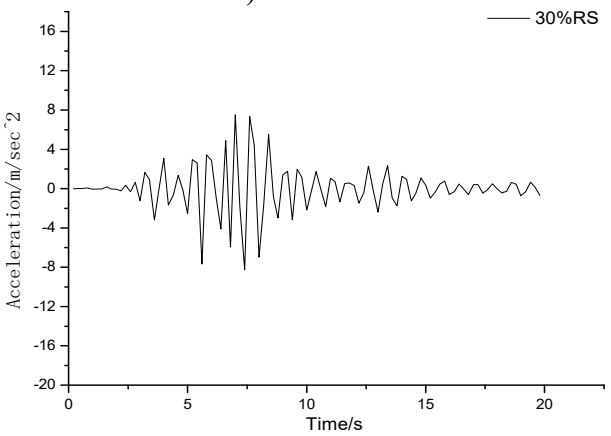

d) $30 \% \mathrm{RS}$

Fig. 9. Time history curves of acceleration at top of foundation pile for different backfill materials

\subsection{Analyses of earth pressure}

Fig. 10 presents layout of survey point for analyses of earth pressure. Fig. 11 present time history curve of earth pressure for different backfill materials. In earthquake, earth pressure will be generated by the backfill soil of abutment foundation due to seismic loads. Fig. 10 indicates the arrangement of measuring points for analyses of earth pressure acting on bridge abutment. Then, the dynamic performance of bridge abutment with four different backfill materials was compared regarding the earth pressure.

Compared to the backfill soil, the sand-rubber mixtures backfill has a higher damping ratio, 
and therefore it can absorb more energy under seismic loads to reduce the earth pressure acting on the bridge abutment. For example, in Fig. 10(a) and (b), the average earth pressure of bridge abutment for $10 \%$ RS was reduced by $46.68 \%$ compared to the backfill soil. As a result, the integrity and stability of the bridge was improved significantly. It is concluded that the sand-rubber mixtures backfill has a great potential in reducing lateral earth pressure for bridge abutment.

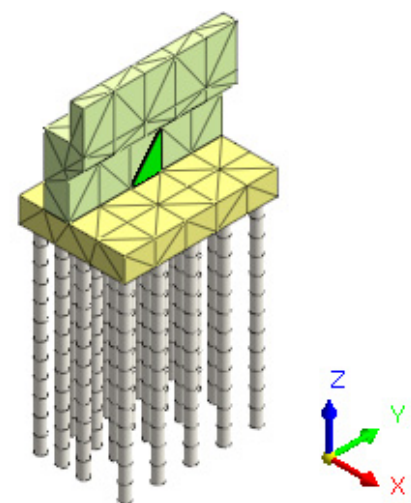

Fig. 10. Layout of survey point for analyses of earth pressure

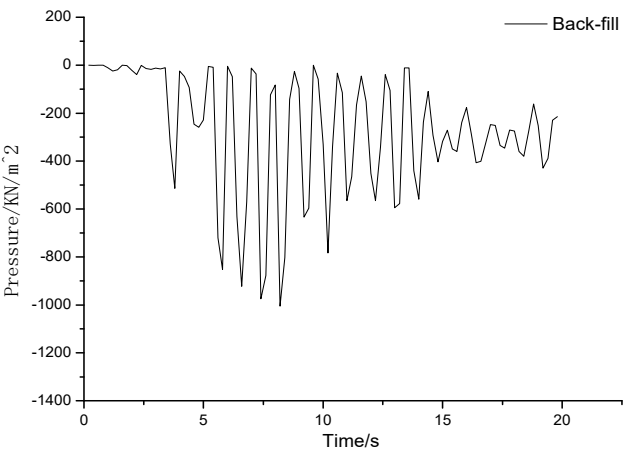

a) Backfill

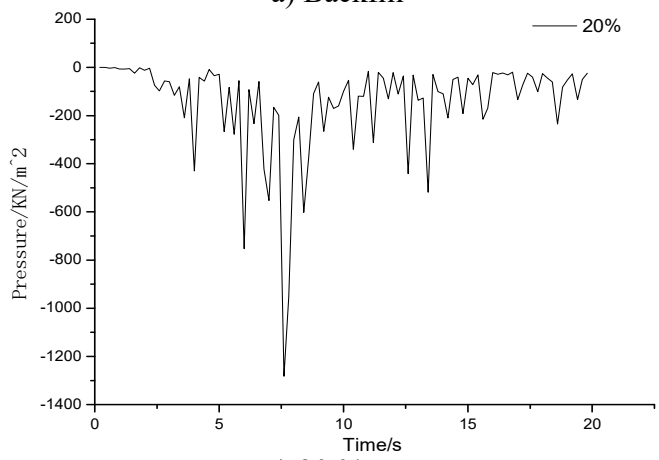

c) $20 \% \mathrm{RS}$

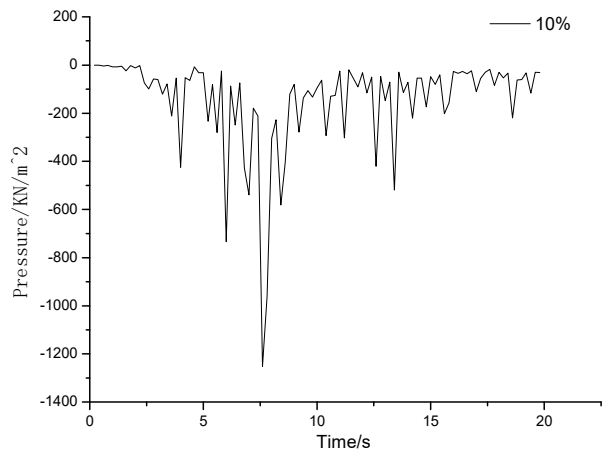

b) $10 \% \mathrm{RS}$

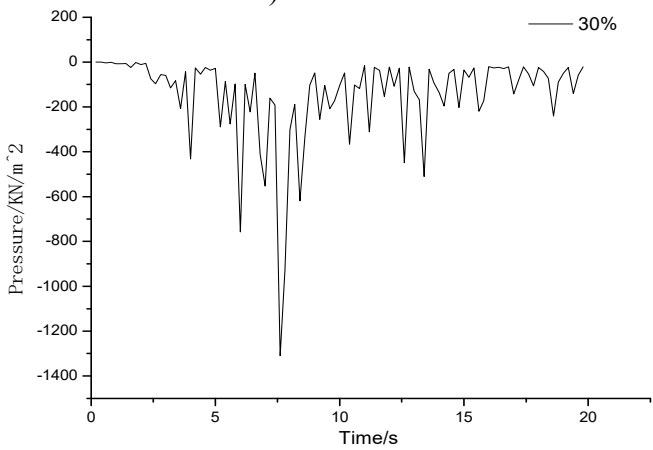

d) $30 \% \mathrm{RS}$

Fig. 11. Time history curve of earth pressure for different backfill materials

\subsection{Analyses of settlement of bridge abutment}

Fig. 12 presents layout of survey point for analyses of settlement of bridge abutment. Fig. 13 present time history curve of settlement of bridge abutment for different backfill materials. Two points were selected on the top and bottom of bridge abutment respectively for settlement analyses as shown in Fig. 12. It is found that the settlements at the top and bottom level of the bridge have 
the same magnitude for four backfill materials. Moreover, the settlement for sand-rubber mixtures backfill was much smaller than that for backfill soil, but there was no much difference of settlement among the three mixtures. The fluctuation of settlement for backfill soil was much greater than the sand-rubber mixtures backfill.

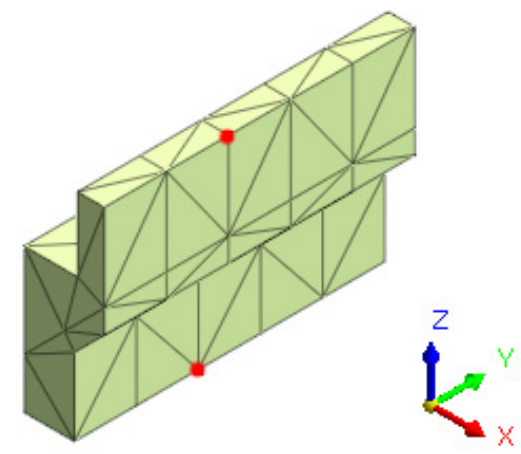

Fig. 12. Layout of survey point for analyses of settlement of bridge abutment

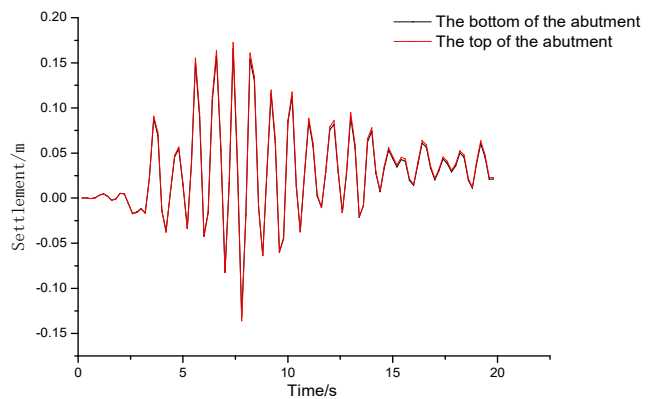

a) Backfill

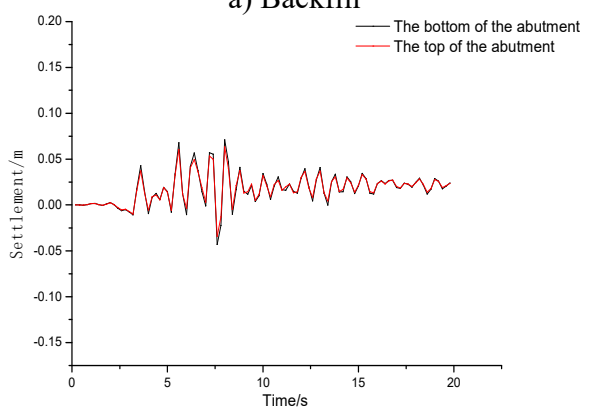

c) $20 \% \mathrm{RS}$

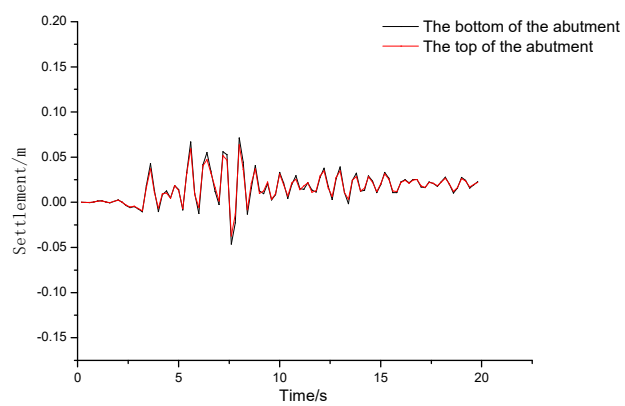

b) $10 \% \mathrm{RS}$

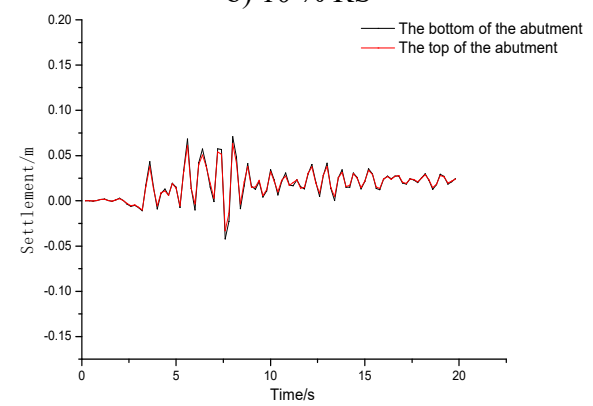

d) $30 \% \mathrm{RS}$

Fig. 13. Time history curve of settlement of bridge abutment for different backfill materials

\subsection{Analyses of abutment acceleration}

Fig. 14 present time history curve of acceleration of bridge abutment for different backfill materials. The same two points (shown in Fig. 12) were selected for the analyses of horizontal acceleration of bridge abutment. Similarly, to the previous analyses of settlement of bridge abutment, the acceleration at top and bottom level of the bridge abutment have the same magnitude for the four backfill materials. In addition, the settlement for sand-rubber mixtures backfill was slightly lower than that for backfill soil, but there was no much difference of acceleration among the three mixtures. The fluctuation of acceleration for backfill soil was greater than the sand-rubber mixtures backfill.

Based on above analyses, it is indicated that the settlement and acceleration of bridge abutment 
for backfill soil are larger than sand-rubber mixtures backfill with rubber content ranging from $10 \%$ to $30 \%$. Furthermore, the volatility of the bridge abutment for backfill soil at top and bottom level are also much larger than the mixtures backfill. This is because the sand-rubber mixtures have a relatively lower shear modulus and a higher damping ratio, thereby it is able to reduce the propagation of seismic wave energy $t$ due to the damping effect. Additionally, since the mixtures also contains fiber which plays a key role in reinforcing the sand and rubber particles in the mixtures, overall bearing capacity of foundation soil is improved, and the settlement of bridge abutment is reduced at both the top and bottom level.

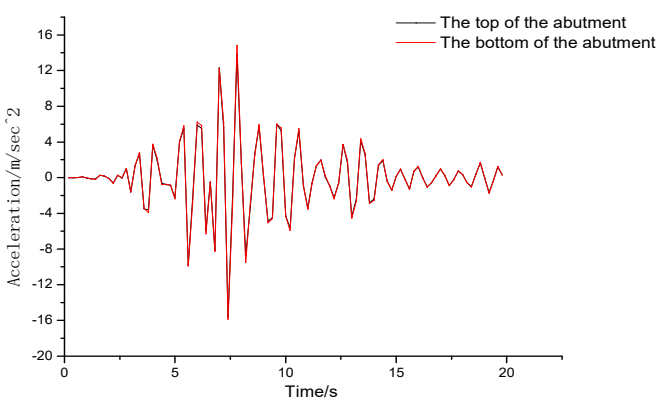

a) Backfill

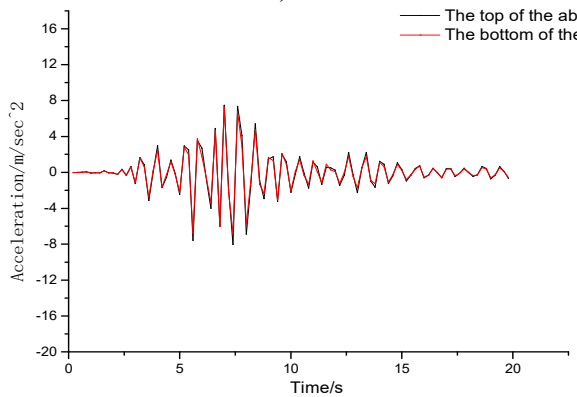

c) $20 \% \mathrm{RS}$

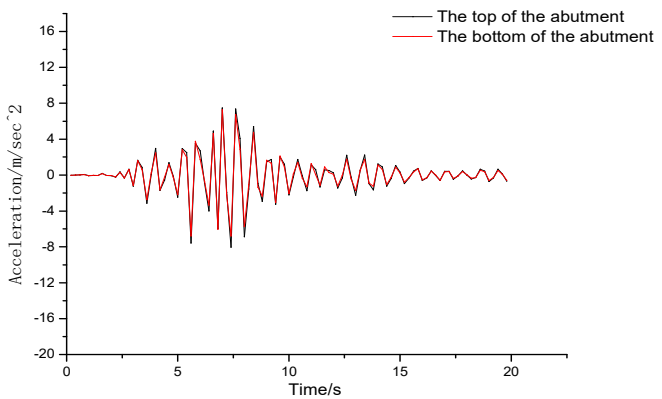

b) $10 \% \mathrm{RS}$

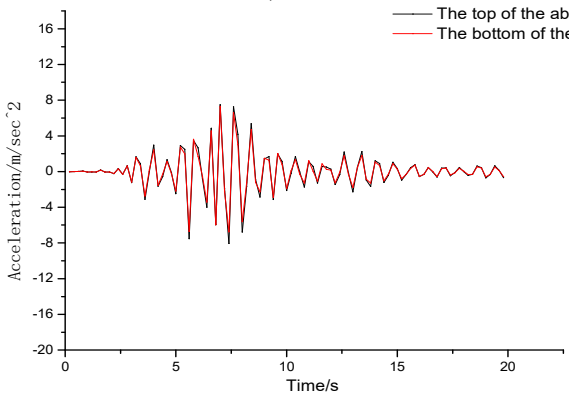

d) $30 \% \mathrm{RS}$

Fig. 14. Time history curves of acceleration of bridge abutment for different backfill materials

\section{Conclusions}

3D FEM simulation of dynamic response of bridge abutment to backfill soil and sand-rubber mixtures backfill under seismic loading conditions was carried out in this study. The simulation results were discussed with respect to ground settlement, ground acceleration, settlement and acceleration at top of foundation pile, earth pressure and settlement and acceleration of bridge abutment. The advantages of using sand-rubber mixtures backfill under seismic loading conditions were also further analyzed and presented. The major conclusions from this study can be drawn as follows:

1. Under the same seismic loads, the sand-rubber mixtures backfill exhibit better performance than backfill soil for bridge abutment. This is because the mixtures have a relatively lower shear modulus and a higher damping ratio. It can minimize the propagation of seismic wave energy due to the damping effect, and reduce the settlement of foundation soil. The fiber added into the mixtures c plays a key role in reinforcing the sand and rubber particles and improving overall bearing capacity of foundation soil.

2. The sand-rubber mixtures with a higher rubber content has a lower shear modulus and higher damping ratio. Derogation seismic energy propagation has a more active role. High levels of sand-rubber containing more fiber reinforcement effect is more obvious, and further improve the rubber filler sand mixed overall bearing capacity. Therefore, using three kinds of sand-rubber mixtures as backfill, settlement and horizontal acceleration of bridge abutment at top of the pile is 
in the order $10 \% \mathrm{RS}>20 \% \mathrm{RS}>30 \% \mathrm{RS}$.

3. Because the sand-rubber has a higher damping ratio, it can absorb more energy under seismic loads to reduce the principal stress of bridge abutment. And the reduction rate of sand-rubber mixtures with time is higher than that of backfill soil.

It is concluded that the sand-rubber mixtures backfill can not only significantly reduce the ground settlement and displacement at top of foundation piles, but also greatly improve the seismic performance of bridge abutment. The sand-rubber composite backfill is helpful to neutralize seismic load during earthquake and protect the bridge structure from potential damage.

\section{Acknowledgements}

This research was financially supported by the Natural Science Foundation of Jiangsu Province (Grant No. BK20161311) and Six Major Talent Peak in Jiangsu Province in China (Grant No. 2015-JZ-011). The authors are grateful to Cheng Lu for his help on this paper.

\section{References}

[1] Ahmadi S. F., Eskandari M. Vibration analysis of a rigid circular disk embedded in a transversely isotropic solid. Journal of Engineering Mechanics, Vol. 140, Issue 7, 2013, p. 04014048.

[2] Pak R. Y. S., Guzina B. B. Seismic soil-structure interaction analysis by direct boundary element methods. International Journal of Solids and Structures, Vol. 36, Issue 31, 1999, p. 4743-4766.

[3] Pak R. Y. S., Jennings P. C. Elastodynamic response of pile under transverse excitations. Journal of Engineering Mechanics, Vol. 113, Issue 7, 1987, p. 1101-1116.

[4] Pak R. Y. S. Asymmetric wave propagation in an elastic half-space by a method of potentials. Journal of Applied Mechanics, Vol. 54, Issue 1, 1987, p. 121-126.

[5] Shodja H. M., Ahmadi S. F., Eskandari M. Boussinesq indentation of a transversely isotropic halfspace reinforced by a buried inextensible membrane. Applied Mathematical Modelling, Vol. 38, Issue 7, 2014, p. 2163-2172.

[6] Eskandari M., Shodja H. M., Ahmadi S. F. Lateral translation of an inextensible circular membrane embedded in a transversely isotropic half-space. European Journal of Mechanics - A/Solids, Vol. 39, 2013, p. 134-143.

[7] Eskandari M., Ahmadi S. F., Khazaeli S. Dynamic analysis of a rigid circular foundation on a transversely isotropic half-space under a buried inclined time-harmonic load. Soil Dynamics and Earthquake Engineering, Vol. 63, 2014, p. 184-192.

[8] Pak R. Y. S. On the flexure of a partially embedded bar under lateral loads. Journal of Applied Mechanics, Vol. 56, Issue 2, 1989, p. 263-269.

[9] Apostoloum Gazetas G., Garini E. Seismic response of slender rigid structures with foundation uplifting. Soil Dynamics and Earthquake Engineering, Vol. 27, Issue 7, 2007, p. 642-654.

[10] Housner G. W. The behavior of inverted pendulum structures during earthquake. Bulletin Seismological Society of America, Vol. 53, Issue 2, 1963, p. 404-417.

[11] Ciampoli M., Pinto P. E. Effects of soil-structure interaction on inelastic seismic response of bridge piers. Journal of Structural Engineering, Vol. 121, Issue 5, 1995, p. 806-814.

[12] Priestley M. J. N., Seibelf Calvi G. M. Seismic Design and Retrofit of Bridges. John Wiley and Sons, New York, 1996.

[13] Makris N., Roussos Y. S. Rocking response of rigid blocks under near-source ground motions. Geotechnique, Vol. 50, Issue 3, 2000, p. 243-262.

[14] Crème C., Pecker A., Davenne L. Modeling of nonlinear dynamic behavior of a shallow strip foundation with macro- element. Journal of Earthquake Engineering, Vol. 6, Issue 2, 2002, p. 175-211.

[15] Gazetas G., Apostolou M. Nonlinear soil-structure interaction: foundation uplifting and soil yielding. Proceedings of the 3rd UJNR Workshop on Soil-structure Interaction, California, USA, 2004, p. 1-16.

[16] Sakellaraki D., Kawashima K. Effectiveness of seismic rocking isolation of bridges based on shake table test. The 1st European Conference on Earthquake Engineering and Seismology, Geneva, Switzerland, 2006, p. 1-10.

[17] Kawashima K., Nagai T., Sakellaraki D. Rocking seismic isolation of bridges supported by spread foundations. Proceedings of the 2nd Japan-Greece Workshop on Seismic Design, Observation and Retrofit of Foundations, Tokyo, 2007, p. 254-265. 
[18] Kawashima K., Watanabe G., Sakellaraki D. Rocking isolation of bridge foundations. The 9th World Seminar on Seismic Isolation, Energy Dissipation and Active Vibration Control of Structures, Kobe, Japan, 2005, p. 609-630.

[19] Wen X., Xu Crane The Present Situation of Waste Tire Resource in China. School of Environmental Science and Engineering, Nankai University, Tianjin, 2006, p. 7-9, (in Chinese).

[20] Tsang H. H. Seismic Isolation by Rubber-Soil Mixtures for Developing Countries. Wiley Inter Science, 2007, p. 284-303.

[21] Ceng G., et al. Foundation Treatment Handbook. China Building Industry Press, Beijing, 1988, (in Chinese).

[22] Gong X. Foundation treatment technology and its development. Journal of Civil Engineering, Vol. 30, Issue 6, 1997, p. 3-11, (in Chinese).

[23] Liang X., Cai Y. Q. Experimental study on dynamic elastic modulus and damping ratio of composite foundation. Journal of Civil Engineering, Vol. 37, Issue 1, 2004, p. 96-101, (in Chinese).

[24] Wang Z. Y., Shen Z. Study on settlement of pavement with solidified flyash backfills adjacent to abutment. Subgrade Engineering, Vol. 148, Issue 1, 2010, p. 59-61, (in Chinese).

[25] Tsang H. H., Lo S. H., Xu X., Sheikh M. N. Seismic isolation for low-to-medium-rise buildings using granulated rubber-soil mixtures: numerical study. Wiley Inter Science, 2012, p. 2010-2024.

[26] Gong X. Composite Foundation Theory and Engineering Application. Zhejiang University Press, Hangzhou, 2002, (in Chinese).

[27] Nakhaee A., Marandi S. M. Reducing the forces caused by earthquake on retaining walls using granulated G rubber-soil mixture. IJE Transactions B: Applications, Vol. 24, Issue 4, 2011, p. 337-350.

[28] Yuan Y. H. Study Sand-Rubber Backfill of Abutment Features. Yancheng Institute of Technology, 2013, (in Chinese).

[29] Choi S. G., Wang K. J., Chu J. Properties of biocemented, fiber reinforced sand. Construction and Building Materials, Vol. 120, 2016, p. 623-629.

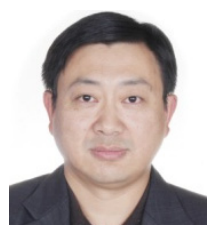

Zhaoyu Wang received Ph.D. degree in civil engineering from Nanjing University of Technology, Nanjing, China, in 2014. Now he works at Yancheng Institute of Technology. His current research interests include civil engineering, dynamics and static finite element analysis.

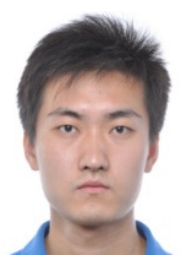

Nan Zhang received Ph.D. degree in civil engineering from University of Texas at Arlington, Arlington, U.S.A, in 2015. Now he works as Postdoctoral Fellow at University of Texas at Arlington. His current research interests include static and dynamic finite element analysis, geothermal engineering, and sensor technology.

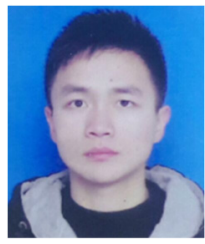

Qi Li received Bachelor degree in Yancheng Institute of Technology, Yancheng, China, in 2015. Now he works at Yancheng Institute of Technology. His current research interests include civil engineering, dynamics and static finite element analysis.

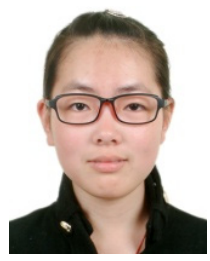

Xiaohui Chen received Bachelor degree in Yancheng Institute of Technology, Yancheng, China, in 2015. Now he works at Yancheng Institute of Technology. His current research interests include control, dynamics and static finite element analysis. 